\title{
EDUCAÇÃO INCLUSIVA PELA IGUALDADE DE OPORTUNIDADES: DEBATE SOBRE GÊNERO E SEXUALIDADE NA ESCOLA
}

\author{
INCLUSIVE EDUCATION FOR EQUAL OPPORTUNITIES: GENDER AND SEXUALITY DEBATE \\ IN SCHOOL
}

\author{
Raynan Henrique Silva Trentim ${ }^{1}$ \\ Tereza Rodrigues Vieira ${ }^{2}$
}

${ }^{1}$ Mestrando em Ciências Jurídicas pela UNICESUMAR; Pós-Graduado em Direito Educacional pela Faculdade Dom Alberto; Bacharel em Direito pela UNIPAR aprovado na OAB. Licenciado em História pelo Centro Universitário Internacional - UNINTER e Pedagogia pela INTERVALE. E-mail: raynantrentim@hotmail.com

2Pós Doutora em Direito pela Université de Montreal, Canadá. Doutora e Mestra em Direito das Relações Sociais pela Pontifícia Universidade Católica de São Paulo (PUC-SP). Especialista em Bioética pela Faculdade de Medicina da Universidade de São Paulo (USP). Docente da disciplina "Tutela Constitucional das Minorias e Grupos Vulneráveis" no Mestrado em Direito Processual na Universidade Paranaense (UNIPAR). Brasil. E-mail: terezavieira@uol. com.br
TRENTIM, R. H. S.; VIEIRA, T. R. Educação inclusiva pela igualdade de oportunidades: debate sobre gênero e sexualidade na escola. Akrópolis Umuarama, v. 27, n. 2, p. 205-215, jul./ dez. 2019.

DOI: 10.25110/akropolis.v27i2.7636

Resumo: O fundamental escopo do presente trabalho é conjeturar acerca da problematização da temática concernente às sexualidades e gêneros no ambiente escolar. Por meio de pesquisa bibliográfica almejase demonstrar que a criança e o adolescente têm direito à informação sobre seu corpo e seu funcionamento, bem como respostas atinentes às sexualidades e aos gêneros. Contudo, o enfoque deverá ser conduzido observando-se aspectos da conduta científica e humanista, evitandose permeio pelo instigado universo do senso comum. A criança e o adolescente têm direito à educação inclusiva, que perpassa e quebra diversos tipos de preconceito e discriminação de caráter sexual e de gênero, uma vez que não se pode labutar na educação ignorando estas manifestações. A legislação zela pela dignidade da criança e do adolescente, portanto a erradicação do preconceito deve ser questão fundamental para a inclusão escolar e o exercício da cidadania sem discriminação.

Palavras-chave: Diversidade; Educação inclusiva; Gênero; Sexualidade.

ABSTRACT: The fundamental scope of the present work is to conjecture about the problematization of the theme concerning sexualities and genders in the school environment. Through bibliographic research aims to demonstrate that children and adolescents have the right to information about their body and its functioning, as well as responses related to sexualities and genders. However, the approach should be conducted by observing aspects of scientific and humanist conduct, avoiding the pervasive universe of common sense. Children and adolescents have the right to inclusive education, which pervades and breaks various types of prejudice and discrimination of a sexual and gender character, since education cannot be ignored by ignoring these manifestations. Legislation ensures the dignity of children and adolescents, so the eradication of prejudice must be a fundamental issue for school inclusion and the exercise of citizenship without discrimination.

KEYWORDS: Diversity; Inclusive education; Genre; Sexuality. 


\section{INTRODUÇÃO}

Não é novidade para nenhum brasileiro a carência do acesso à educação de qualidade para todos. Projetos pedagógicos com o objetivo de incrementar a base curricular compromissada com a inclusão e sociabilização dos estudantes são discutidos, porém rejeitados sem percucientes debates pela base política conservadora, machista e heteronormativa.

Atualmente, as crianças apresentam-se mais questionadoras que nunca, principalmente quando se deparam com as diferenças anatômicas genitais. Daí resulta a necessidade de se trabalhar a sexualidade da criança na escola, sobretudo quando envolve a identidade de gênero, embora esta tenha início antes da criança chegar aos bancos escolares. Segundo Bee (2003, p.338), "o gênero se torna uma força ainda mais poderosa para orientar o comportamento e as atitudes por volta dos cinco ou seis anos".

Freud (1923/1962), ao seu turno, em Trois essais sur la théorie de la sexualité, entende que as inquirições iniciais são sempre sexuais, vez que a criança necessita determinar o seu lugar no mundo e esse espaço é um lugar sexual. Ao abordar a sexualidade, todo adulto, seja professor ou pai, depara-se com sua própria infância recalcada, podendo acarretar prejuízo ao aprendizado da criança. É aconselhável ao adulto se autoanalisar para trabalhar com as crianças.

Perante a homogeneidade da conjuntura familiar, torna-se complexo aos pais explanarem questões concernentes aos conceitos de aceitação do próprio corpo e, assim, romper preconceitos. Há, também, insuficiente informação científica para elucidação apropriada de pontos que exigem maiores conhecimentos e desprovimento de timidez sobre temas relativos à temática sexual e de gênero.

Considerando que a sexualidade humana, ao longo da história, foi objeto de mistificações e restrições tornando-se um tabu que persiste até os dias atuais, os grupos sociais e científicos que buscam esclarecer questões, condutas e identidades referentes à temática têm seu campo de trabalho obstaculizado pelo setor conservador e fundamentalista da sociedade.

A escola e a família deixam "marcas" na criança e no adolescente, pois moldam seu caráter no que tange aos aspectos éticos e morais, bem como a maneira de compreender e intera- gir com o mundo. Evidencia-se, assim, que os jovens acabam por absorver informações equivocadas e insuficientes sobre temáticas relacionadas à educação sexual e gênero, e a partir disso, a escola tem o dever de elucidar questionamentos sobre esse assunto. Cabe ao setor educacional exercer sua função socializadora, uma vez que o acesso à educação é uma garantia constitucional e uma obrigação dos pais e do Estado, os quais devem assegurar que a informação e o conhecimento, em sua plenitude, alcancem a todos (BRASIL, 1988).

É de conhecimento geral, as adversidades motivadas pela falta de informação e repressão aos temas ligados à sexualidade, porém, muitos pais e instituições de ensino se omitem deste necessário debate, por equivocadamente acreditarem que preconizarão a prática sexual e até mesmo, de alguma forma, induzir os jovens às relações homossexuais. Evidentemente, as temáticas vinculadas à sexualidade e ao gênero, não incentivam a prática sexual, mas preconizam o conhecimento do próprio corpo e demonstram a diversidade que constrói a identidade de cada indivíduo.

O conservadorismo ainda tem impedido que a sexualidade e o gênero sejam discutidos de forma ampla e aberta. Logo, essa omissão mantém os jovens na ignorância e contribui com os casos de gravidez indesejada e o aumento de contágio de doenças sexualmente transmissíveis (DST's), ocasionados pelas relações sexuais desprotegidas, e até mesmo, impossibilita a compreensão dos jovens acerca das identidades e diversidade sexual existentes perpetuando o preconceito ou concepções equivocadas.

Assim, é de extrema importância o enfoque desta temática nos espaços educacionais, vez que visa a garantir maior informação aos jovens, pautando questões de saúde, prevenção, e inclusive, fomentar o exercício da cidadania e do respeito tornando-os cidadãos capazes de propagar a equidade de direitos a pluralidade existente no âmbito social. Destarte, torna-se necessário apresentar possibilidades a esses jovens de perceber e ampliar as múltiplas formas de existência e, para isso, os educadores devem ter conhecimento das relevantes questões arguidas. 

2 PRECONCEITO E DISCRIMINAÇÃO: É POS-
SÍVEL SUPERAR?

Ainda é comum a reprodução de piadas vexatórias de grupos considerados inferiores socialmente. Por meio desse humor "sem graça", revela o preconceito com grupos LGBT e muIheres, reafirmando historicamente como grupos socialmente oprimidos.

O termo 'preconceito' possui em sua definição a ideia de alguma opinião dada ou sentido concebido sem exame crítico. Em outras palavras, é a compreensão equivocada, opinião desfavorável formada sem conhecimento, sem razão e sem ponderar sobre o assunto, que gera um sentimento hostil de intolerância generalizada pelo meio ou como a pessoa se impõe socialmente. Assim, entre os diversos tipos de preconceito, há o "sexual, que se refere a determinado gênero- em geral o feminino- ou a uma identidade sexual considerada desviante (como dos homossexuais)" (CARVALHO, 2012, p. 157).

$\mathrm{Na}$ análise acerca dessas condições desprivilegiadas, Carvalho (2012) assevera que o preconceito possui três componentes: Cognitivo (ideias e crenças negativas), afetivas (sentimento de desprezo, ódio e medo) e comportamentais (predisposição em discriminar). Por isso, quando se aponta uma conduta homofóbica em um indivíduo, por exemplo, há uma grande possibilidade de este sujeito ser e ter uma predisposição à homossexualidade, pois no quesito afetivo pode-se existir o medo de se aceitar acabando por cometer a discriminação.

Apesar das similaridades, há diferença entre a discriminação e o preconceito, pois este se baseia em ideias e crenças, enquanto que a discriminação é dada por ações e práticas. Então, o preconceito pode ser compreendido como a delimitação no plano cognitivo de ações reprováveis, se restringindo ao plano das ideias. Ao passo em que a discriminação sucede quando a pessoa se utiliza do campo prático para exteriorizar o preconceito existente em si, executando-0 .

O direito penal não consegue alterar a subjetividade das pessoas. Na realidade, esta não é sua preocupação, pois rege a punição como o ato de discriminar, portanto, a partir do momento em que esta ocorre, o direito penal se preocupa com uma resposta ao agente que comete tal ato.

No âmbito social, qualquer meio de pre- conceito e discriminação é preocupante, principalmente quando estes são naturalizados, uma vez que o núcleo familiar possui grande importância na formação do indivíduo, e muitas vezes, durante este processo, concepções equivocadas e preconceituosas são transmitidas aos ascendentes, e dessa forma evidencia-se a necessidade dos ambientes escolares fomentarem debates sobre o tema e incluí-lo nos espaços e nas salas de aula. Não há que se olvidar que:

Quando tais preconceitos passam a ser normativos, isto é, viram regras, as expectativas e as exigências das autoridades e dos seus pares criam pressões e induções ao conformismo. Desse modo, uma tradição cultural de preconceito pode adquirir grande força e persistência. É por essa razão que muitas ações de combate aos diferentes tipos de preconceito se desenvolvem no ambiente escolar, pois é um dos principais espaços em que acontecem a socialização dessas crenças e ideias e o constrangimento social, a fim de que os indivíduos as aceitem como válidas (CARVALHO, 2012, p. 132).

Este é o eterno desafio, visto que alguns municípios estão proibindo conteúdo relativo às temáticas de gênero e sexualidade nas escolas, vedando a circulação de materiais didáticos vindos do governo federal. Nesse sentido:

Falar sobre gênero nas escolas é uma forma de eliminar o preconceito e prevenir a discriminação e a violência. Não falar sobre gênero nas escolas é o mesmo que "lavar as mãos" diante do preconceito, que gera tanto sofrimento, afinal, o silêncio é instrumento e cúmplice da violência (BRASIL, 2016).

Lidar com questões de gênero e sexualidade nos espaços educacionais não se trata de submeter às crianças e jovens a um processo sexualizador. Apenas os instruem acerca de seus corpos, desejos e vontades, além de exercer a empatia e torná-los mais receptivos à diversidade, e consequentemente, superando a onda de intolerância que assola nosso país.

Afirma-se aqui que os educadores não desejam determinar o gênero dos alunos, mas asseverar, transversalmente ou por intersecção, que as mulheres têm os mesmos direitos que os 
homens e que se deve considerar e acolher o direito à diversidade, respeitando as liberdades individuais. As pessoas LGBTI não são anormais nem doentes. Afiançar isto não visa acabar com as famílias e nem ensinar as crianças a serem gays. $\mathrm{O}$ intuito é evidenciar o direito à igualdade e às oportunidades entre os gêneros, demonstrando que as desigualdades nascem com o preconceito (VIEIRA, TRENTIM, 2019).

Cumpre mencionar, que, no dia 6 de abril de 2017, o Ministério da Educação brasileiro alterou o texto da nova versão da Base Nacional Curricular que servirá como supedâneo para o ensino nas escolas públicas e privadas, subtraindo todas as expressões "identidade de gênero" e "orientação de gênero" (CANCIAN, 2017).

Não há como observar com bons olhos as atitudes de muitas prefeituras no Brasil, bem como do próprio Ministério da Educação, os quais proíbem o debate sobre gênero e sexualidade nas escolas. Iniciar o combate ao problema desde cedo e desconstruir preconceitos não tem idade para aprender.

\section{GÊNERO E SEXUALIDADE: PRESSUPOS- TOS LIGADOS À EDUCAÇÃO E AO DIREITO}

O dever de educar confere aos pais e mestres a obrigação de não se restringir ao conteúdo meramente didático e incluir questões sociais pertinentes para o desenvolvimento da cidadania dos jovens. Contudo, na maioria dos casos, temas ligados à educação sexual e gênero são deixados de lado, o que acaba por favorecer o senso comum, e consequentemente, a manutenção de concepções errôneas e preconceituosas que enfraquecem o diálogo sobre saúde, subjetividades e identidades.

Se pensarmos que, de acordo com a legislação brasileira, o Ensino Fundamental é obrigatório, poderemos supor que, ao menos em tese, todas as crianças e os/as adolescentes frequentam a escola em algum momento da sua vida. Assim sendo, a ampla gama de diversidade cultural, sexual, social, étnico-racial, entre outras, está presente na escola, que precisa encontrar maneiras de lidar com as diferenças sem que elas se transformem em motivos de preconceito ou discriminação. Em outras palavras, pessoas de orientações sexuais e identidades de gênero diversas frequentam a esco- la e devem ter sua sexualidade e suas identidades respeitadas. Este é também um exercício de cidadania (BRASIL, 2015, p.2).

O cerne da questão reside no fato de que o jovem não possui qualquer aparato que possa explicar ou solucionar suas dúvidas referentes ao sexo e à sexualidade, pois sua estigmatização corrobora com a censura e o senso comum. Assim, a educação tem que respaldar esta temática de maneira ampla, garantindo que a informação chegue a todos em sua plenitude, uma vez que a educação para criança e adolescentes é uma obrigação do Estado e dos pais.

Não é despiciendo lembrar que:

O tema educação é tratado de forma clara em todas as constituições brasileiras, bem como nas discussões internacionais. A educação adquiriu espaço nas constituições brasileiras de modo a expandir o conhecimento da sociedade brasileira, tendo o Estado obrigação de oferecer um sistema educacional a todos, independentemente de quaisquer fatores ou condições. Deve direcionar valores monetários para a estruturação escolar. A constituição atual não deixou apenas para o Estado o dever de educar, impondo essa responsabilidade, também, aos familiares, buscando, uma parceria entre Estado e família (SOUZA \& SANTANA, 2010, s/p).

O Direito Educacional, como direito social que é, recebe de cada um dos três poderes da União: Legislativo, Executivo e Judiciário suas parcelas de responsabilização, mobilizando, assim, todas as esferas governamentais. Isso demonstra a importância de se ter acesso à educação, uma vez que, conforme preconiza o Art. 205 da Constituição Federal:

A educação, direito de todos e dever do Estado e da família, será promovida e incentivada com a colaboração da sociedade, visando ao pleno desenvolvimento da pessoa, seu preparo para o exercício da cidadania e sua qualificação para o trabalho" (BRASIL, 1988).

Considerando que o dever de educar não se restringe aos espaços educacionais, mas atribui responsabilidade aos núcleos familiares 
também, pode-se afirmar que a escola e o seio familiar exercem a função de moldar o caráter da criança e do adolescente, seus valores éticos e a maneira que compreende e interage com o mundo.

Por sua abrangência, importância e adequação ao tema tratado no presente trabalho, além do art. 205, mister se faz aqui salientar o disposto no caput e em alguns dos incisos do artigo 206, da Constituição Federal (1988), assemelhando-se ao disposto na Lei n. 9.394/1996, Lei de Diretrizes e Bases da Educação Nacional (art. $3^{\circ}$., LDB):

Art. 206. O ensino será ministrado com base nos seguintes princípios:

I - igualdade de condições para o acesso e permanência na escola;

II - liberdade de aprender, ensinar, pesquisar e divulgar o pensamento, a arte e o saber;

III - pluralismo de ideias e de concepções pedagógicas, e coexistência de instituições públicas e privadas de ensino.

No entender de Isabella Bana (2016, p. 88):

Os dispositivos constitucionais citados explicitam o dever do Estado, claramente desempenhado pelas instituições de ensino, e o direito de qualquer pessoa à educação, com o fito essencial de promover o desenvolvimento integral do ser humano, bem como a sua cidadania. É nítida que qualquer espécie de discriminação - exclusão, distinção ou limitação por motivo de sexo, orientação sexual, gênero, raça, etnia, cor, religião, condição social, entre outras - deve ser repudiada e afastada, cabendo ao Estado - escola pública ou privada - garantir as condições para que todos os indivíduos possam estudar e permanecer no ambiente escolar, com fulcro na tolerância, na igualdade, no respeito, na liberdade e na própria dignidade da pessoa humana.

Mostra-se assustador constatar que no século $X X I$, a sexualidade e o gênero ainda não são tratados de forma respeitosa e adequada nas escolas. Ao não se ensinar e discutir a temática sobre gênero com a criança e o adolescente eles irão aprendê-la de forma preconceituosa e praticarão chacotas com os outros. Assim, "não podem pais ou professores fugir a função de educadores. Se educam em outros setores, se lecionam outros assuntos e matérias, não podem fugir do imperativo de transmitir conhecimentos de ordem sexual" (CERQUEIRA, 2011, p. 261).

A educação enfatizando a temática sexualidade/gênero é voltada para esclarecer questões ligadas a preconceitos, tabus e violências relacionados às discussões que preconizam esses assuntos. Um dos seus objetivos é responder indagações de maneira natural e em conformidade com a idade, utilizando a devida metodologia pedagógica, inserida cuidadosamente no contexto escolar, com uma abordagem interdisciplinar e lúdica, bem como esclarecer dúvidas sobre preservativos, DST's, organismo masculino e feminino, anticoncepcionais, gravidez e respeito à diversidade.

Tais pressupostos encontram-se respaldos nos aspectos jurídicos, onde o direito à educação é um direito social contemplado na Constituição de 1988 (BRASIL, 1988), contudo, anteriormente, o Estado não se via obrigado a promover uma educação inclusiva para todos. A educação tinha um papel assistencial, onde o ensino público era destinado somente para aqueles que não tinham recursos para custeá-lo.

No sentido estrito e formal, a educação tem por finalidade o pleno desenvolvimento da criança e do adolescente na sua inserção social, sua qualificação profissional e para o exercício da cidadania.

Inclusive, deve-se mencionar que o Estatuto da Criança e do Adolescente (BRASIL, 1990), repudia e pune qualquer tipo de discriminação e preconceito contra os destinatários desta lei. Frise-se:

Considera-se criança até 12 anos incompletos e adolescentes de 12 a 18 anos. É dever da família, comunidade, sociedade e do poder público assegurar os direitos à vida, saúde, alimentação, educação, esporte, lazer, profissionalização, cultura, dignidade, respeito, liberdade e convivência familiar. Estes direitos serão prioritários nas políticas públicas. Nenhuma criança ou adolescente deve sofrer negligências, discriminação, exploração etc. (FERNANDES \& PALUDETO, 2010, p. 243).

Permitir que uma criança sofra bullying em espaços educacionais pelo fato de demons- 
trar comportamento homoafetivo ou identidade transgênero é um desrespeito à dignidade desse menor.

Ademais, não é despiciendo lembrar que a Lei de Diretrizes e Bases, incluiu em 2018 em seu artigo 12, inciso IX, ao prever as incumbências dos estabelecimentos de ensino, respeitadas as normas comuns e as do seu sistema de ensino, o dever de "promover medidas de conscientização, de prevenção e de combate a todos os tipos de violência, especialmente a intimidação sistemática (bullying), no âmbito das escolas" (BRASIL, 2018).

Razão assiste à Isabella Bana (2016, p. 87), quando esta afirma:

É possível vislumbrar ainda que tais condutas de bullying tornam-se cada vez mais constantes e "normais" em decorrência, principalmente, da permissividade das instituições de ensino, que acreditam na inexistência desse fenômeno no âmbito escolar e consideram referidas agressões como "normais"e "próprias da idade", impossibilitando qualquer atuação preventiva e educativa. Assim, resta evidente que o bullying não consiste numa fase saudável de desenvolvimento da criança e do adolescente, mas, pelo contrário, traduz-se num gravíssimo problema social - transgressor do valor supremo e dos direitos fundamentais, especialmente à educação.

Deve-se combater o desrespeito e a intolerância e não permitir que a subjetividade seja alvo de um sistema coercitivo informal em um espaço que possui a obrigação de ensinar valores humanísticos de boa convivência.

Desse modo, é dever da escola, com o auxílio do corpo docente e demais funcionários, prezar pelo combate ao preconceito e buscar um ambiente mais receptivo à diversidade. Entretanto, tal realidade ecoa como algo distante, pois infelizmente, ainda, nos deparamos com algumas escolas que proíbem às pessoas transgênero o uso do banheiro de acordo com sua identidade de gênero. Inclusive, muitos docentes se recusam a tratar o aluno transgênero pelo nome social, causando constrangimentos a estes indivíduos. A educação contribui também para:

[...] exercitar o respeito, a tolerância, a promoção e a valorização das diversidades (étnico-racial, religiosa, cultural, geracional, territorial, físico-individual, de gênero, de orientação sexual, de nacionalidade, de opção política, [...] (FERNANDES e PALUDETO, 2010, p. 233).

A educação é um dos principais meios de construção de valores e a ética ligada à filosofia e à área humanística traz a noção de que inexiste verdade absoluta, pois esta depende de atributos subjetivos, ou seja, independentemente da crença que a pessoa tenha esta merece respeito, uma vez que a liberdade está acima de imposição cultural e de valores internos de cada um. O estudo da ética não pode ser negligenciado.

Cumpre lembrar que:

A reflexão ética traz à luz a discussão sobre a liberdade de escolha. A ética interroga sobre a legitimidade de práticas e valores consagrados pela tradição e pelo costume. Abrange tanto a crítica das relações entre os grupos, dos grupos nas instituições e ante elas, quanto à dimensão das ações pessoais. Trata-se, portanto, de discutir o sentido ético da convivência humana nas suas relações com várias dimensões da vida social: o ambiente, a cultura, o trabalho, o consumo, a sexualidade, a saúde (FERNANDES \& PALUDETO, 2010, p. 241).

Como pontuada na Lei de Diretrizes e Bases da Educação (LDB), Lei 9.394, de 20 de dezembro de 1996, em seu artigo 2:

A educação, dever da família e do Estado, inspirada nos princípios de liberdade e nos ideais de solidariedade humana, tem por finalidade o pleno desenvolvimento do educando, seu preparo para o exercício da cidadania e sua qualificação para o trabalho (BRASIL, 1996).

O acesso universal à educação não pode ser restrito ou atenuado, o direito ao conhecimento deve ser amplo e permitir que assuntos pertinentes às crianças e aos jovens sejam tratados na escola.

Sexualidade/gênero é um assunto de extrema importância para o autoconhecimento do indivíduo e também para o respeito à diversidade. Assim, enquanto ainda existir, nos espaços 
escolares, homossexuais, travestis e transexuais sofrendo violência, principalmente institucional, não se pode afirmar que a educação é um direito de todos.

A Lei de Diretrizes e Bases da Educação (BRASIL, 1996) se baseia em diversos princípios, dentre eles destaca-se a igualdade de condições para o acesso e permanência na escola. Em assim sendo, o Estado deveria cumprir seu papel garantindo o acesso e também a permanência de grupos minoritários no ambiente escolar, tratando a todos com igualdade. A grande evasão escolar por parte das pessoas travestis é a prova de que o Estado está muito distante de promover a igualdade. Conforme apresenta o defensor público João Paulo Carvalho Dias, $82 \%$ das travestis e transexuais se encontram distantes das instituições de ensino, seja por preconceitos associados às suas identidades, ou por não chegarem até estes espaços (ALMEIDA, 2016).

Outro princípio muito pertinente que consta também na LDB encontra-se presente no artigo $3^{\circ}$, II, a respeito da liberdade e apreço à tolerância. Vejamos:

Os direitos humanos devem fazer parte do processo educativo das pessoas. Para defender seus direitos, todas as pessoas precisam conhecê-los e saber como reivindicá-los na sua vida cotidiana. Além disso, a educação em direitos humanos promove o respeito à diversidade (étnico-racial, religiosa, cultural, geracional, territorial, de gênero, de orientação sexual, de nacionalidade, de opção política, dentre outras), a solidariedade entre povos e nações e, como consequência, o fortalecimento da tolerância e da paz (RIZZI, 2011, p. 16).

Assim, evidencia-se que a educação baseada nos direitos humanos é um grande desafio para o nosso século e, conteúdos ligados à sexualidade e o gênero não podem ficar fora desta pauta.

\section{RELAÇÕES SOCIAIS E FEMINISMO: AS- PECTOS DE GÊNERO}

A socióloga Berenice Bento assevera que as relações não surgem espontaneamente, mas são impostas desde o nascimento. A identidade sexual inscreve-se, exaustivamente, por meio de repetições e de códigos socialmente investidos como naturais (BENTO, 2006). Essas interações, imposições e regras ditas masculinas e femininas geram preconceitos e suscitam desigualdade latente.

Desde o século passado os brasileiros têm observado algumas conquistas referentes à igualdade social entre homens e mulheres, tais como o direito ao voto, à educação superior, ao trabalho e paridade salarial, e recentemente, a criminalização da violência doméstica e do feminicídio, que consiste no agravante do homicídio, por motivo fútil ou torpe por vulnerabilidade de gênero.

Essa igualdade material que vem sendo buscada é o principal objetivo do feminismo, que consiste em um movimento com inspirações políticas, sociais, filosóficas e ideológicas que vem reivindicar direitos iguais e a libertação de padrões opressores. Ressalte-se aqui que:

A violência de gênero se baseia na de-
sigualdade entre homens e mulheres,
construída historicamente. Por isso, no
Brasil, desde 2006, existe a Lei Ma-
ria da Penha, exatamente para punir a
violência doméstica e familiar contra as
mulheres, baseada em gênero. Ou seja,
baseada na desigualdade entre homens
e mulheres. "Bater em mulher" antiga-
mente, era visto como um problema
menor, porque não se percebia o quanto
ela é séria. Inúmeras pesquisas também
revelam o alto índice de morte de mulhe-
res, travestis e transexuais, vítimas da
violência de gênero. A dimensão deste
problema só ficou clara por causa dos
debates sobre gênero (BRASIL, 2016 ,
p. 1).

O feminismo pode ser considerado o movimento que veio para realizar a quebra da superioridade baseada no gênero. Luta por uma sociedade igualitária, e já no século passado não lutava somente por causa própria, mas incluiu demandas LGBTs, combatendo o preconceito em todos os campos do gênero.

Por muito tempo, as pessoas que sofreram violência, baseada em gênero (entre elas, as mulheres, os gays, as lésbicas, os/as travestis e os/as transexuais) ficaram caladas, escondidas e com medo até mesmo de falar sobre seus desejos e sobre suas dúvidas, in- 
clusive nas escolas. A discussão sobre gênero nas escolas não é para impor nada a ninguém. É somente uma forma de refletir sobre os problemas que podem ser gerados pelo estabelecimento de papéis tão rígidos para os homens e as mulheres, em nossa sociedade. A partir das discussões sobre gênero, podemos falar mais abertamente sobre promoção da saúde, a superação da vulnerabilidade às doenças sexualmente transmissíveis, a prevenção do abuso sexual infantil, a prevenção do assédio sexual, a gravidez entre adolescentes, sobre machismo, sexismo, racismo, entre tantos outros temas. Foi também a partir das discussões sobre gênero que pudemos pensar sobre feminilidades e masculinidades e as diversas formas de expressão da sexualidade e dos modos de ser homem ou mulher, que mudam ao longo da história, de cultura para cultura, de pessoa para pessoa. Estudar sobre gênero na escola favorece, assim, a prática do respeito entre meninos e meninas, homens e mulheres (BRASIL, 2016, p. 3).

No ano de 2006, foi criada a Lei Maria da Penha, com o intuito de punir a violência doméstica e familiar contra mulheres. Essa violência se baseia na desigualdade entre homens e mulheres construídas socialmente. A figura do 'homem', antigamente, o estabelecia como provedor da casa, colocando a mulher em situação de serventia e inferioridade e, a qualquer sinal de desobediência, as mulheres eram comumente agredidas. Desse modo, a violência era considerada como algo naturalizado, quase insignificante, e a sociedade não atribuía a devida importância.

Afirmava-se também, a ideia de que mulher não poderia sentir prazer e que o sexo possuía a finalidade única de procriação e satisfação do homem. Atribuíam às mulheres, que exploravam sua sexualidade, o título de pessoa vulgar, totalmente fora dos padrões, além de proibi-las a ter relações sexuais. Ressalte-se, portanto que, o gênero está

[...] diretamente relacionado à sexualidade porque, antigamente, havia uma ideia de que o sexo era apenas para ter filhos. A única prática sexual aceita era a heterossexual. Quem não se encaixava neste padrão de gênero, era considera- do anormal. Por isso, aquelas pessoas que não querem ter filhos e as pessoas que não se encaixam no padrão heterossexual, como as lésbicas, os gays e os bissexuais sofrem tanto preconceito e tanta violência (BRASIL, 2016).

Levantamento realizado pelo Grupo Gay da Bahia, sob a direção do sociólogo Luis Mott, indica que aumentou o índice de morte de travestis e transexuais, vítimas de violência motivada por gênero (NúMERO, 2016). Para se ter um parâmetro acerca dos dados desta violência, estima-se que a expectativa de vida de uma travesti hoje é de 35 anos, enquanto a expectativa de vida de um brasileiro 'comum' a média geral é de 79 anos (BORTONI, 2017).

Ressalte-se, também, a vulnerabilidade das pessoas transgênero que convivem diariamente com o preconceito e situações de discriminação, considerando que o mercado de trabaIho não as acolhe, gerando a grande desistência dessas pessoas em conquistar espaços acadêmicos e científicos. Resta como única alternativa a prostituição. Infelizmente, são excepcionais os casos em que uma travesti ou transexual não se submete à prostituição e conquista um emprego formal, pois as condições socioculturais de hoje ainda impõem esta realidade.

A realidade é muito cruel com as minorias, principalmente com as travestis e transexuais. Percebe-se que o machismo persiste e causa danos vultosos e a sociedade está em um lento processo de evolução, onde se percebe pequenas conquistas de espaços para estes grupos. Educação que aborda a sexualidade e gênero seria um divisor de águas, quando trabaIhada em consonância com uma educação pedagógica e inclusiva, dentro do contexto escolar, que reestruturaria a sociedade de maneira mais tolerante e harmoniosa.

\section{ESTATUTO DA DIVERSIDADE SEXUAL E DE GÊNERO}

Em 2011, o Conselho Federal da Ordem dos Advogados do Brasil (OAB) nomeou uma Comissão Especial da Diversidade Sexual, sob a presidência de Maria Berenice Dias (OAB-RS), para elaboração de um Estatuto da Diversidade Sexual objetivando a proteção dos direitos das pessoas homossexuais, lésbicas, bissexuais, transexuais, travestis, intersexuais e assexuais, 
consideradas minorias sexuais. Como consultores, foram indicados pela Ordem dos Advogados do Brasil: Luis Roberto Barroso (então advogado inscrito na OAB-RJ), Daniel Sarmento (OAB-RJ), Tereza Rodrigues Vieira (OAB-SP) e Rodrigo da Cunha Pereira (OAB-MG), uma vez que ao Estado incumbe proporcionar políticas de igualdade de oportunidades, enfrentamento e superação das desigualdades em razão do preconceito e da discriminação por orientação sexual e de gênero.

De lege ferenda, no que concerne ao direito à educação, propõe o anteprojeto do Estatuto da Diversidade Sexual e Gênero (Projeto de Lei 134/2018, com tramitação no Senado), que os estabelecimentos de ensino devem coibir no ambiente escolar, condutas que visem intimidar, ameaçar, constranger, ofender, castigar, submeter, ridicularizar, difamar, injuriar, caluniar ou expor aluno a constrangimento físico ou moral, em decorrência de sua orientação sexual ou identidade de gênero. Referido Estatuto chegou ao Senado após 100 mil assinaturas terem sido subscritas em um abaixo-assinado, tornando-se o Projeto de Lei PLS 134/2018, que além de prever o Estatuto da Diversidade Sexual e de Gênero, determina penas em caso de preconceito e intolerância em virtude da sexualidade, além de instrumentos para salvaguardar a igualdade de oportunidades e direitos das minorias.

Estabelece, igualmente, que os profissionais da educação têm o dever de abordar as questões de gênero e sexualidade sob a ótica da diversidade sexual, objetivando superar toda forma de discriminação, fazendo uso de material didático e metodologias que proponham a eliminação da homofobia e do preconceito. Devem os estabelecimentos de ensino adotar materiais didáticos que não reforcem a discriminação com base na orientação sexual ou identidade de gênero.

As escolas, ao programarem atividades referentes a datas comemorativas, devem atentar à multiplicidade de formações familiares, de modo a evitar qualquer constrangimento dos alunos filhos de famílias LGBTI.

Os professores, diretores, supervisores, psicólogos, psicopedagogos e todos os que trabalham em estabelecimentos de ensino têm o dever de evitar qualquer atitude preconceituosa ou discriminatória contra alunos filhos de famílias LGBTI.

É assegurado, nos estabelecimentos de ensino fundamental e médio e nos cursos superiores, aos transexuais, travestis e intersexuais, desde o ato da matrícula e a qualquer tempo, o uso do nome social, o qual deverá constar em todos os registros acadêmicos. O pedido será formulado por escrito pelo próprio aluno. Não há a necessidade de o pedido ser requerido pelos pais ou responsáveis, ainda que o aluno seja menor de idade ou incapaz.

A educação continua sendo um caminho para o respeito ao direito ao livre desenvolvimento do gênero, da sexualidade e da identidade. Deve o professor receber formação adequada, com estratégias pedagógicas e psicopedagógicas para o convívio com a diversidade, de modo a contribuir para a prevenção e a eliminação do preconceito baseado na visão binária e heteronormativa da sexualidade (VIEIRA, TRENTIM, 2019).

Não pode a escola ser um ambiente a serviço da heteronormatividade e que objetiva a normalização de corpos, subjetividades, alimentando preconceitos e segregações, muito menos protegendo a "pedagogia do insulto" em que piadas, agressões veladas ou não, configuram o espaço escolar como ambiente da intolerância, tornando-o insuportável para pessoas LGBTI+ (GÊNERO, VIEIRA, 2019).

Destarte, incumbe ao poder público a promoção da capacitação dos professores para uma educação inclusiva, bem como ações com o objetivo de elevar a escolaridade de homossexuais, lésbicas, bissexuais, transexuais, travestis e intersexuais, no intuito de evitar a evasão escolar.

\section{CONSIDERAÇÕES FINAIS}

O desenvolvimento social no Brasil ocorre a passos muito lentos. Os grupos minoritários tratados neste artigo possuem uma história de luta e pouquíssimos direitos, conquistados à duras penas. Considere-se que, o sistema político sempre foi regido por pessoas que, sem o devido conhecimento científico e desprovidas de sensibilidade, decidiam arbitrariamente sobre essas questões.

Ao longo do estudo, restou claro que a criança, tanto quanto o adolescente têm direito à educação inclusiva que aborda temas de sexualidade e de gênero de maneira pedagógica e em conformidade com a sua faixa etária, quebrando barreiras e preconceitos preordenados impositi- 
vamente.

Por vezes, os pais, na busca de proteger seus filhos, acabam criando diferenciações de gênero, influenciando comportamentos preconceituosos sem nenhuma base científica.

A escola é o lugar onde se deve falar sobre a diversidade, pois a homogeneidade do contexto escolar é riquíssima e a escola não pode se abster do imperativo de ensinar ou ignorar as situações de bullying e discriminação. As crianças e adolescentes carecem desses ensinamentos de ordem sexual e de gênero.

Contudo, não se pode dizer que se precisa, necessariamente, de uma disciplina específica para esse tema. A abordagem de forma interdisciplinar demonstrará, desde cedo, que a educação deve ser voltada para os direitos humanos e respeito pelo diferente.

Destarte, o ambiente escolar é um dos espaços pertinentes para abarcarmos as discussões de gênero e sexualidade, pois nas relações entre os sujeitos, independentemente de suas localizações, são produzidos preconceitos, questionamentos, inquietações e violências contra as diferenças que compõem o contexto social e educacional.

Conclui-se que, não há como trabalhar a educação de crianças e adolescentes, ignorando as manifestações da sexualidade e o respeito ao diferente, visto que, são aspectos importantes do seu desenvolvimento, agregando dinâmica no ensino de aprendizagem.

\section{REFERÊNCIAS}

ALMEIDA, A. Evasão escolar entre travesti é bem maior. Faculdade Latino-Americana de Ciências Sociais. 2016. Disponível em: http:// flacso.org.br/?p=15833. Acesso em: 04 ago. 2018.

BANA, I. Bullying, homofobia e responsabilidade civil das escolas. São Paulo: Boreal, 2016, 159p.

BEE, H. A criança em desenvolvimento. 9 ed. Porto Alegre: Artmed, 2003.

BENTO, B. Corpos e próteses: dos limites discursivos do dimorfismo. Seminário Internacional Fazendo Gênero 7: Gênero e Preconceito. 2006. Disponível em: www. fazendogenero7.ufsc.br/. Acesso em: 20 jun.
2019.

BORTONI, L. 35 anos é a expectativa de vida do transexuais no Brasil. Geledés Instituto da mulher negra. 2017. Disponível em: https:// www.geledes.org.br/35-anos-e-expectativa-devida-de-transexuais-no-brasil/ . Acesso em: 02 ago. 2018.

BRASIL. Constituição (1988). Constituição da República Federativa do Brasil: promulgada em 5 de outubro de 1988. Disponível em: http:// www.planalto.gov.br/ccivil_03/constituicao/ constituicaocompilado.htm. Acesso em: 02 jul. 2018.

Estatuto da criança e do adolescente: Lei Federal n 8.069/90. Diário Oficial da União, Brasília, 16 Jul.1990.

\section{Estatuto da Diversidade Sexual.}

elaborado pela Comissão Especial da Diversidade Sexual, nomeada pelo Conselho Federal da Ordem dos Advogados do Brasil, através da Portaria n. 16/2011, de 15 abril de 2011. Maria Berenice Dias (Presidenta), Adriana G. M. Abílio, Jorge Marcos Freitas, Marcos V. T. Pereira, Paulo T. Mariante, Daniel Sarmento, Luis Roberto Barroso, Rodrigo da Cunha Pereira e Tereza Rodrigues Vieira (SP)1ª.versão, 2011.

Gênero nas Escolas: duas décadas de ações pelo fim do preconceito no Brasil. 2016. Disponível em: https://www.dropbox.com/ s/567dmv9u0yf7q5w/folder-especial-formatocartilha.pdf?dl=0. Acesso em: 02 fev. 2017.

Lei $n^{\circ}$ 9.394, de 20 de dezembro de 1996. Estabelece as diretrizes e bases da educação nacional. Diário Oficial da União, Brasília. 23 dez. 1996.

BRASIL. Lei. 13.663, de 14 de maio de 2018, que altera o art. 12 da Lei. 9.394, de 20 de dezembro de 1996, para incluir a promoção de medidas de conscientização, de prevenção e de combate a todos os tipos de violência e a promoção da cultura de paz entre as incumbências dos estabelecimentos de ensino. Diário Oficial da União de 15.5.2018.

BRASIL. Ministério da Educação. Gênero e Educação. Orientação sexual e a identidade de gênero na escola. 2015. Disponível em: 
http://generoeeducacao.org.br/wp-content/ uploads/2015/11/Orienta\%C3\%A7\%C3\%A3osexual-e-a-identidade-de-g\%C3\%AAnero_ GDE1.pdf. Acesso em: 18 fev. 2018.

CAMINHADA trans: de que lado você está? Carta Capital. Disponível em: https://www. cartacapital.com.br/sociedade/mulheres-ehomens-trans-na-luta-por-seus-direitos. Acesso em: 20 Mar 2018.

CANCIAN, N. Ministério tira 'identidade de gênero' e 'orientação sexual da base curricular. Folha de São Paulo. 2017. Disponível em: https://www1. folha.uol.com.br/educacao/2017/04/1873366ministerio-tira-identidade-de-genero-eorientacao-sexual-da-base-curricular.shtml. Acesso em: 06 abr. 2018.

CARVALHO, A. P. C. et al. Desigualdades de gênero, raça e etnia. Curitiba: Intersaberes, 2012.

CERQUEIRA, E. K. et al. Sexualidade, gênero e desafios bioéticos. São Caetano do Sul: Difusão Editora, 2011. 261 p.

FERNANDES, A. V. M.; PALUDETO, M. C. Educação e direitos humanos: desafios para a escola contemporânea. Cad. Cedes, Campinas, vol. 30, n. 81, p. 233-249, 2010.

FINCO, D. Relações de gênero nas brincadeiras de meninos e meninas na educação infantil. Pro-Posições. v. 14, n. 3, p. 89-99, 2003.

FREUD, S. Trois essais sur la théorie de la sexualité. Tradução do alemão por Blanche Reverchon-Jouve, Collection Idées. Paris: Gallimard,1923/1962.

GÊNERO, I. K.; VIEIRA, T. R. A utilização de banheiros públicos ou de acesso ao público pela população trans. In: Transgêneros, coordenação de Tereza Rodrigues Vieira. Brasília: ZK, 2019.
RIZZI, E. G.; GONZALES, M.; XIMENES, S. B. Direito humano à educação. (org.) Plataforma Dhesco Brasil e Ação Educativa. Comunicare Gráfica, 2011, 48p.

SOUZA, M. C.; SANTANA, J. M. A. M. P. O direito à educação no ordenamento constitucional brasileiro. In: Âmbito Jurídico, Rio Grande, XIII, n. 74, mar 2010. Disponível em: http://www.ambitojuridico.com.br/site/index.php?n_link=revista artigos_leitura\&artigo_id=7368. Acesso em: $0 \overline{1}$ jul. 2016.

VIEIRA, T. R.; TRENTIM, R. H. S. Direito à diversidade sexual e à identidade de gênero livremente manifestadas. In: Transgêneros, coordenação de Tereza Rodrigues Vieira. Brasília: ZK, 2019.

\section{EDUCACIÓN INCLUSIVA PARA IGUALDAD DE OPORTUNIDADES: DEBATE DE GÉNERO Y SEXUALIDAD EN LA ESCUELA}

Resumen: El alcance fundamental del presente trabajo es conjeturar sobre la problematización del tema relacionado con las sexualidades y los géneros en el entorno escolar. A través de la investigación bibliográfica, se pretende demostrar que los niños y adolescentes tienen derecho a la información sobre su cuerpo y su funcionamiento, así como a las respuestas relacionadas con las sexualidades y los géneros. Sin embargo, el enfoque debe realizarse observando aspectos de la conducta científica y humanista, evitando el universo dominante del sentido común. Los niños y adolescentes tienen derecho a una educación inclusiva, que impregna y rompe varios tipos de prejuicios y discriminación de carácter sexual y de género, ya que la educación no puede ser ignorada ignorando estas manifestaciones. La legislación garantiza la dignidad de los niños, niñas y adolescentes, por lo que la erradicación de los prejuicios debe ser un tema fundamental para la inclusión escolar y el ejercicio de la ciudadanía sin discriminación.

Palabras clave: Diversidad; Educación inclusiva; Género; Sexualidad.
NÚMERO de homicídios de pessoas LGBT pode ser recorde em 2016. Folha PE. 2016. Disponível em: http://www.folhape. com.br/noticias/noticias/brasil/2016/12/29/ NWS, 12148,70,450,NOTICIAS,2190-NUMEROHOMICIDIOS-PESSOAS-LGBT-PODE-SERRECORDE-2016.aspx. Acesso em: 29 dez. 2018. 